Check for updates

Cite this: RSC Adv., 2018, 8, 4703

\title{
Occurrence of pharmaceuticals and personal care products, and their associated environmental risks in Guanting Reservoir and its upstream rivers in north China†
}

\author{
Panwei Zhang, (DD ab Huaidong Zhou, ${ }^{\text {ab }}$ Kun Li, ${ }^{\text {ab }}$ Xiaohui Zhao, ${ }^{\text {ab }}$ Qiaona Liu, ${ }^{\text {ab }}$ \\ Dongjiao Li, ${ }^{\text {b }}$ Gaofeng Zhao*ab and Liang Wang ${ }^{\mathrm{b}}$
}

Eighteen selected pharmaceuticals and personal care products (PPCPs), consisting of five non-antibiotic pharmaceuticals (N-APs), four sulfonamides (SAs), four tetracyclines (TCs), four macrolides (MCs), and one quinolone (QN) were detected in surface water and sediments from Guanting Reservoir (GTR) and its upstream rivers in north China. Acetaminophen, caffeine, chlorotetracycline, and ofloxacin were detected with $100 \%$ frequency in the surface water of GTR and its upstream rivers, while diltiazem was also detected with $100 \%$ frequency in surface water from the reservoir's upstream rivers. Acetaminophen and caffeine were detected with $100 \%$ frequency in sediments from GTR and its upstream rivers, while high concentrations of ofloxacin in GTR, and carbamazepine, tetracycline, and chlortetracycline in upstream rivers were also detected in $100 \%$ of samples. Five N-APs, especially acetaminophen and caffeine, were prominent pollutants. The mean concentrations of acetaminophen were 155 and $302 \mathrm{ng} \mathrm{L}^{-1}$ in surface water and 529 and $202 \mathrm{ng} \mathrm{g}^{-1}$ in sediments from GTR and upstream rivers, respectively. The mean concentrations of caffeine were 208 and $338 \mathrm{ng} \mathrm{L}^{-1}$ in surface water samples and 1430 and $1020 \mathrm{ng} \mathrm{g}^{-1}$ in sediments from GTR and upstream rivers, respectively. The geographical differences in PPCP concentrations were largely due to anthropogenic activities. Sewage discharged from Zhangjiakou City and human activities around the GTR basin were the main sources of PPCPs in this area. An environmental risk assessment for the worst-case scenario was undertaken using calculated risk quotients, which indicated a medium risk from erythromycin in GTR and a high risk in its upstream rivers.

Received 1st December 2017 Accepted 16th January 2018 DOI: $10.1039 / c 7 r a 12945 a$

rsc.li/rsc-advances residues released into the municipal waste stream. ${ }^{5}$ PPCP residues, which are only partially removed during wastewater treatment, can be discharged to the aquatic environment. ${ }^{6}$ Waste byproducts, such as sewage sludge and manures, could also transfer a variety of human and veterinary pharmaceutical residues into the environment following their land application. ${ }^{7}$

PPCPs in the aquatic environment mainly originated from several sources. Most PPCPs are sewage derived from human and animal sources, which were partly eliminated in wastewater treatment process, and input the ambient surface water, finally. The input of PPCPs also could be via surface runoff from agricultural fields, which was confirmed by evidence that sediment concentrations of PPCPs in agriculture-influenced rivers were greater than those in the overlying water matrix. ${ }^{8}$ Aquacultural industry is another source of PPCPs in the aquatic environment. The pharmaceuticals were used in aquaculture could be transported directly into surface water or accumulate in the sediment. ${ }^{9}$ As a result of inputs from both human and animal sources, PPCPs have been frequently detected in the aquatic environment. Many PPCPs have been detected in sewage effluent, ${ }^{10,11}$ river water, ${ }^{12,13}$ lake water, ${ }^{14,15}$ and estuarine and
${ }^{a}$ State Key Laboratory of Simulation and Regulation of Water Cycle in River Basin, China Institute of Water Resources and Hydropower Research, Beijing, 100038, China. E-mail: zhaogf@iwhr.com; Fax: +86-10-68573618; Tel: +86-10-68781893

${ }^{b}$ Department of Water Environment, China Institute of Water Resources and Hydropower Research, Beijing, 100038, China

$\dagger$ Electronic supplementary information (ESI) available. See DOI: 10.1039/c7ra12945a 
coastal water. ${ }^{16,17}$ Although PPCPs are typically present in the aquatic environment at trace concentrations (from a few to several $\mu \mathrm{g} \mathrm{L}^{-1}$ ), these levels are insufficient to pose a great threat to ecosystems or exposed organisms. ${ }^{18}$ Many PPCPs are persistent in the environment, and once assimilated they have the potential to bio-accumulate in organisms, which may cause antibiotic resistance, endocrine disruption, inhibition of primary productivity, and other effects. ${ }^{\mathbf{1 9 2 0}}$ Therefore, the occurrence, distribution, migration, transformation, and potential risks of PPCPs in aquatic environments have become an important issue.

China, the largest developing country in the world, is undergoing rapid economic and social development. ${ }^{\mathbf{1 4}}$ The consumption of PPCPs has increased rapidly in last 20 years in China. China is also the third-largest retail market and manufacturer of PPCPs in the world, being outranked only by the United States and Japan. ${ }^{21}$ As the increasing concern over the potential environmental risks of PPCPs, many studies have been conducted to investigate their occurrence, spatial distribution, fate, and effects in the environment in China. PPCPs residues have been reported in the Yangtze River Estuary, ${ }^{\mathbf{1 4 , 1 5}}$ Yellow River, ${ }^{22}$ Pearl River Delta, ${ }^{23}$ Taihu Lake, ${ }^{24}$ Baiyangdian Lake, ${ }^{25}$ and offshore areas of the Bohai Sea and Yellow Sea. ${ }^{10}$

Guanting Reservoir (GTR), the second largest natural freshwater in north China, is facing serious pollution. Lots of pollutants are widespread in GTR. ${ }^{26,27}$ Although contamination in GTR is frequently reported, there have been few reports of PPCPs in this area. The aim of this study was to investigate their occurrence and distribution in the surface water and sediments of GTR. The study also investigated the potential hazards of selected PPCPs for aquatic ecosystem, which will provide important data for decision makers in this region.

\section{Materials and methods}

\section{Reagents}

HPLC-grade methanol and acetonitrile were purchased from Fisher Scientific International Inc. (Pittsburgh, PA, USA); formic acid (98\%) was purchased from Dikma (Lake Forest, CA, USA); citric acid (99\%) and sodium hydrogen phosphate (99\%) were purchased from Sigma-Aldrich (St. Louis, MO, USA). De-ionized (DI) water $\left(>18.2 \mathrm{M} \Omega \mathrm{cm}^{-1}\right.$ ) was prepared with the Milli-Q Advantage A10 system (Millipore, Billerica, MA, USA).

Eighteen PPCP compounds (acetaminophen [ACE, 99.5\%], caffeine [CAF, 98.5\%], diltiazem [DTZ, 99.0\%], carbamazepine [CBZ, 99.5\%], fluoxetine [FXT, 99.0\%], sulfadiazine [SDZ, 99.0\%], sulfamethoxazole [SMX, 99.5\%], sulfamethazine [SMZ, 99.6\%], trimethoprim [TMP, 99.5\%], oxytetracycline [OTC, 96.5\%], tetracycline [TC, 98.0\%], chlorltetracycline [CTC, 93.0\%], doxycycline [DOX, 98.7\%], azithromycin [AMZ, 97.0\%], erythromycin [ERY, 99\%], tylosin [TYL, 98.0\%], lincomycin [LIN, 99.0\%], and ofloxacin [OFL, 99.0\%]) were purchased from Dr. Ehrenstorfer GmbH (Augsburg, Germany). The basic information of the eighteen selected PPCPs was showed in Table S1 in ESI. $\dagger$

Isotope-labeled compounds were used as surrogate standards $\left(100.0 \quad \mu \mathrm{g} \quad \mathrm{L}^{-1}\right.$ in methanol). Sulfadimidine $-{ }^{13} \mathrm{C}_{6}$ $\left(\right.$ SMZ $\left.^{13} \mathrm{C}_{6}\right)$, erythromycin- ${ }^{13} \mathrm{C}, \mathrm{d}_{3}\left(\mathrm{ERY}^{-13} \mathrm{C}, \mathrm{d}_{3}\right)$, and atrazine- $\mathrm{d}_{5}$ $\left(\right.$ ATZ- $\left.\mathrm{d}_{5}\right)$ were purchased from WITEGA Laboratorien BerlinAdiershof GmbH (Berlin, Germany).

\section{Sample collection}

Guanting Reservoir (GTR) is located in Beijing and Zhangjiakou in Hebei province. Its surface area is almost $130 \mathrm{~km}^{2}$, and its main tributary is the Yongding River, which accepts water from Sanggan River and Yanghe River. GTR is the second largest water source for industrial and agricultural purposes in Beijing. The reservoir was a source of drinking water for Beijing before 1997. However, industrial and farming pollution have substantially degraded the quality of water in the reservoir. ${ }^{26,27}$ The Winter Olympic Games will be held in Beijing and Zhangjiakou in 2022, and the water quality in GTR will be an important issue.

Sampling was performed from GTR as well as its upstream rivers in August 2017. The sampling map and a detailed site description are provided in Fig. 1 and Table S2 in ESI. $\dagger$ A total of 28 water samples (L01-L14 located in GTR, R01 located in Guishui River, R02, R03 located in Yongding River, R04, R05 located in Shanggan River, R06-R09, R11, R12 located in Yanghe River, R10 located in Qingshui River, R13 located in Nanyanghe River, R14 located in Dongyanghe River) and 23 sediment samples (L05 in GTR and R05, R09, R12, R14 in rivers were not obtained) were collected in the sampling. All samples were placed on ice and transported to the laboratory as soon as possible after collection. Surface water samples were collected from each sampling site with a stainless steel bucket which had been pre-cleaned with methanol and DI water, and then rinsed twice with water from the sampling site before collection. Water samples were kept at $4{ }^{\circ} \mathrm{C}$ and target PPCPs were extracted from water samples within four days. Sediments were collected with a stainless steel grab from the surface sediment, and were freeze-dried, ground, passed through a 200-mesh sieve, and kept at $-20{ }^{\circ} \mathrm{C}$ prior to analysis.

\section{Sample preparation and analysis}

Chemical analysis was performed following United States Environmental Protection Agency (USEPA) method 1694 with some modifications. ${ }^{28}$ Surface water samples were filtered through glass fiber filters ( $\mathrm{GF} / \mathrm{F}, 0.7 \mu \mathrm{m}$. Whatman, Maidstone, UK). Eighteen selected PPCPs were extracted from water samples by using solid phase extraction (SPE) apparatus (Supelco, Bellefonte, PA, USA), with hydrophilic-lipophilic balance (HLB) sorbents cartridge (6 mL, $500 \mathrm{mg}$; Waters, Milford, MA, USA), and from sediment with an ultrasonic-assisted extraction and then purified using a HLB cartridge.

Water. Surface water samples $(1000 \mathrm{~mL})$ were filtered through a Whatman ${ }^{\circledR}$ grade $\mathrm{GF} / \mathrm{F}$ glass fiber filter to remove visible particles. Before extraction with an Oasis HLB cartridge, $500 \mathrm{mg}$ of $\mathrm{Na}_{2}$ EDTA and $50 \mathrm{ng}$ of surrogate standards $\left(\mathrm{SMZ}^{-13} \mathrm{C}_{6}, \mathrm{ERY}^{-13} \mathrm{C}, \mathrm{d}_{3}, \mathrm{ATZ}-\mathrm{d}_{5}\right.$ ) were added to $1000 \mathrm{~mL}$ water samples. The HLB cartridges were preconditioned sequentially with $10 \mathrm{~mL}$ methanol, $10 \mathrm{~mL}$ DI water and $10 \mathrm{~mL}$ of $10 \mathrm{mM} \mathrm{L}^{-1}$ $\mathrm{Na}_{2}$ EDTA ( $\mathrm{pH}$ 3.0) solution. After loading samples, HLB cartridges were rinsed with $5 \mathrm{~mL}$ of $5 \%$ methanol aqueous solution and $10 \mathrm{~mL}$ of DI water and vacuum-dried for $15 \mathrm{~min}$. 


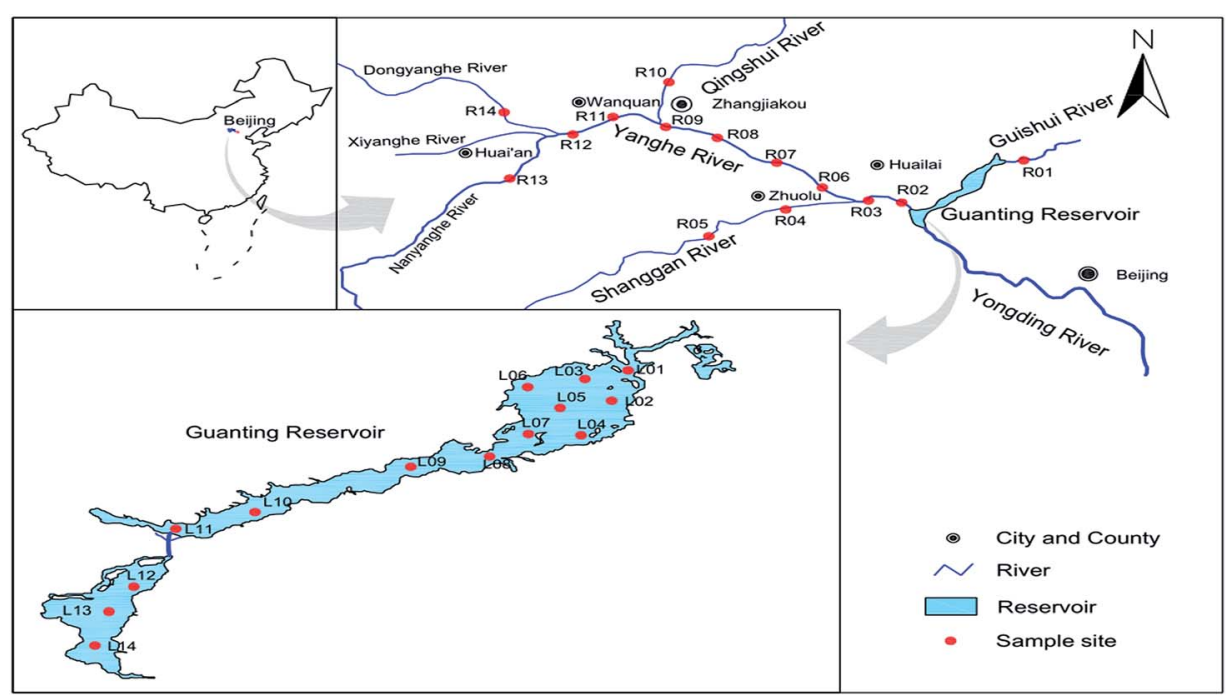

Fig. 1 Location of the surface water and sediment sampling sites in GTR and its upstream rivers, China (L01-L14 located in GTR, R01-R14 located in upstream rivers).

Finally, the HLB cartridges were eluted with $10 \mathrm{~mL}$ of methanol and $5 \mathrm{~mL}$ methanol containing 5\% ammonium hydroxide. All the eluates were concentrated to near dryness with a stream of nitrogen in a $50{ }^{\circ} \mathrm{C}$ water bath. The extract was brought to $1 \mathrm{~mL}$ with the mobile phase, and the extraction will be filtered through a $0.22 \mu \mathrm{m}$ filter and ready for analysis.

Sediment. A total of $2.0 \mathrm{~g}$ of pretreated lyophilized sample was spiked with $50 \mathrm{ng}$ of surrogate standards $\left(\mathrm{SMZ}^{13} \mathrm{C}_{6}\right.$, ERY- ${ }^{13} \mathrm{C}, \mathrm{d}_{3}$, ATZ- $\mathrm{d}_{5}$ ) before being fully mixed with $5 \mathrm{~g}$ of EDTAwashed diatomite from Varian (Walnut Creek, KS, USA). The mixture was placed into a $50 \mathrm{~mL}$ conical flask. Then $30 \mathrm{~mL}$ of extraction buffer $(\mathrm{pH}=5)$ consisting of $5 \mathrm{~mL}$ of $0.1 \mathrm{M} \mathrm{Na}_{2}$ EDTA, $10 \mathrm{~mL}$ of citrate buffer (10.5 $\mathrm{g}$ citric acid and $35.8 \mathrm{~g}$ sodium hydrogen phosphate were weighed in a $500 \mathrm{~mL}$ volumetric flask, then brought to $500 \mathrm{~mL}$ with the DI water), and $15 \mathrm{~mL}$ methanol were added to the conical flask. Each sample was vibrated at $250 \mathrm{rpm}$ for $15 \mathrm{~min}$, ultrasonically extracted for $15 \mathrm{~min}$ in an ultrasonic cleaner, and centrifuged at $6000 \mathrm{rpm}$ for $5 \mathrm{~min}$ in a high speed centrifuge. The supernatant was decanted into a $250 \mathrm{~mL}$ glass bottle. The extraction process was repeated two more times and the supernatants were combined into the glass bottle. The supernatant was concentrated to nearly $10 \mathrm{~mL}$ using a rotary evaporation apparatus, and the residue was brought to $250 \mathrm{~mL}$ with DI water. A strong anion exchange (SAX) cartridge (3 mL, $200 \mathrm{mg}$, Dikma, Lake Forest, CA, USA) and the Waters Oasis HLB cartridge were connected in tandem to extract PPCPS from the solution. Matrix interferences by adsorbing anionic humic particles from the sediment extracts was reduced by SAX cartridge, preventing contamination, blocking, and overloading of the HLB cartridge. ${ }^{29}$ The diluted extracted solution was passed through the cartridges at a flow rate of nearly $10 \mathrm{~mL} \mathrm{~min}^{-1}$. The SAX cartridge was discarded after sample loading, and then the HLB cartridge was washed with $5 \mathrm{~mL}$ of $5 \%$ methanol aqueous solution and $10 \mathrm{~mL}$ of DI water and vacuum-dried for $15 \mathrm{~min}$. Finally, the processing steps of HLB cartridges were the same as the water samples.
Dissolved organic carbon (DOC) content was analyzed using a Total Organic Carbon (TOC) analyzer (Vario TOC, Elementar, Co., Germany). Total nitrogen (TN), total phosphorus (TP), and $\mathrm{NH}_{3}-\mathrm{N}$ were analyzed using test ' $\mathrm{N}$ ' tube test kits and a DR 2800 spectrophotometer (HACH Company, Loveland, CO, USA).

\section{High performance liquid chromatography tandem mass spectrometry (HPLC-MS/MS)}

Eighteen selected PPCPs and three surrogate standards (SMZ- ${ }^{13} \mathrm{C}_{6}$, ERY- ${ }^{13} \mathrm{C}, \mathrm{d}_{3}$, ATZ-d ${ }_{5}$ ) were analyzed by HPLC-MS/MS. The HPLC separation was conducted using an Agilent 1290 series instrument equipped with Zorbax Eclipse Rapid Resolution $\mathrm{HD} \mathrm{C}_{18}$ column $(2.1 \times 100 \mathrm{~mm}, 1.8 \mu \mathrm{m}$ : Agilent, Santa Clara, CA, USA). The column was maintained at $30{ }^{\circ} \mathrm{C}$ during sample analysis. The mobile phase consisted of eluent A $(0.1 \%$ formic acid in DI water) and eluent B (acetonitrile). The injection volume was $10 \mu \mathrm{L}$. The separation of PPCPs was achieved using the following gradient program: $0-5 \mathrm{~min}, 15 \% \mathrm{~B}$ with a flow rate of $0.2 \mathrm{~mL} \mathrm{~min}^{-1} ; 5.1 \mathrm{~min}, 15 \% \mathrm{~B}$ with a flow rate of $0.3 \mathrm{~mL} \mathrm{~min}^{-1}$; 5.1-12 $\mathrm{min}, 15-40 \% \mathrm{~B} ; 12-15 \mathrm{~min}, 40-15 \% \mathrm{~B}$. The system was re-equilibrated for $5 \mathrm{~min}$ between runs.

Mass spectrometric analyses were performed by an Agilent 6460 triple quadrupole mass spectrometer equipped with an electrospray ionization source, operated in the positive ionization mode. The nebulizer pressure was set to 35 psi and the flow rate of the drying gas was set to $10 \mathrm{~L} \mathrm{~min}^{-1}$. The capillary and nozzle voltages were 3500 and $0 \mathrm{~V}$, respectively. Sample acquisition was performed in the multiple reaction monitoring (MRM) mode, by recording twice per compound except for FXT, which was recorded just once. The details of the parameters are shown in Table S3 in ESI. $\dagger$

\section{Quality assurance and quality control (QC)}

In a preliminary experiment, the recoveries of the analytical method were assessed by analyzing spiked samples, with 


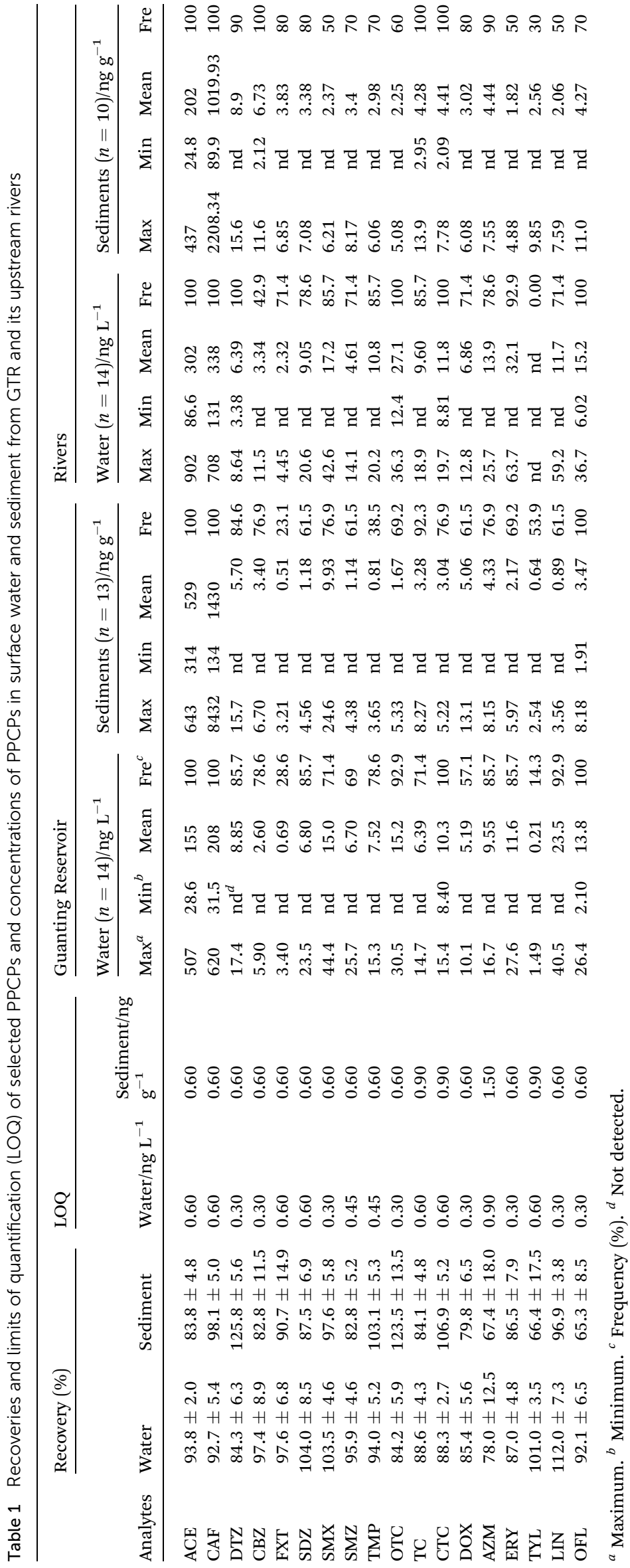


a known amount of standards. For water samples, the mean relative recoveries of three replicates spiked at $50 \mathrm{ng} \mathrm{\textrm {L } ^ { - 1 }}$ varied from 78.0 to $112.0 \%$, with relative standard deviations (RSDs) ranging from 2.0 to $12.5 \%$ for triplicate samples. Sediment samples were spiked at $50 \mathrm{ng} \mathrm{g}^{-1}$ and analyzed in triplicate. The mean and RSD of recoveries were calculated using the average of triplicates and ranged from 65.3 to $125.8 \%$, with RSDs ranging from 3.5 to $18.0 \%$ for triplicate samples. The details of the recoveries and limit of quantification (LOQ) of selected PPCPs and three surrogate standards are provided in Table 1. The LOQ was determined as the concentration at which the signal-to-noise ratio $(\mathrm{S} / \mathrm{N})$ was $>3$. For every set of 10 samples, solvent blanks, procedural blanks, and matrix spikes as well as QC samples were included in the extraction and analysis. The data were not corrected with surrogate recoveries. CBZ was detected in several methods and solvent blanks at very low concentration, with the concentration of $0.3 \mathrm{ng} \mathrm{L} \mathrm{L}^{-1}$, which were subtracted from the corresponding samples before quantification.

\section{Environmental risk assessment}

The potential environmental risks of the detected PPCPs were assessed based on the risk quotient (RQ) method, following the Technical Guidance Document on Risk Assessment from the European Commission. ${ }^{30}$ The RQ values for the PPCPs were calculated using the measured environmental concentration (MEC) divided by the predicted no effect concentration (PNEC). The PNEC of the detected PPCPs was taken from the literature when available. Where a value could not be found in the literature, the PNEC was calculated from the EC50/LC50 divided by an assessment factor of 1000 using only short term/acute toxicity data. When long-term/chronic toxicity data was available, the PNEC was calculated from the lowest no observed effect concentration (NOEC) divided by an assessment factor of 100,50 , or 10 for one, two, or three trophic levels respectively. According to the calculated RQ values, the environmental risks were classified into low risk (0.01-0.1), medium risk (0.1-1), and high risk (>1) levels. ${ }^{31}$

\section{Statistics}

The mean and maximum concentrations and detection frequencies of PPCPs were calculated using Microsoft Excel 2007. The Pearson correlation analysis between PPCP concentrations and water quality parameters was performed using SPSS Ver.17.0 (IBM, Armonk, NY, USA).

\section{Results and discussion}

\section{PPCPs in surface water}

The concentrations of PPCPs in surface water samples from GTR and its upstream rivers are summarized in Table 1. The eighteen surveyed PPCPs were all detected above the limit of quantification (LOQ) in surface water samples from GTR and its upstream rivers. In GTR, ACE, CAF, CTC, and OFL were detected in all surface water samples, while the detection frequency of the other target PPCPs was above 50\%, except for FXT (28.6\%) and TYL (14.3\%). With the exception of FXT and TYL, the other sixteen target PPCPs were frequently detected (50-100\%) in surface water. CAF was the most abundant PPCP, with the highest mean concentration of $208 \mathrm{ng} \mathrm{L}^{-1}$, followed by ACE, with a mean concentration of $155 \mathrm{ng} \mathrm{\textrm {L } ^ { - 1 }}$ in GTR. The mean concentrations of FXT and TYL were only 0.69 and $0.21 \mathrm{ng} \mathrm{L}^{-1}$, respectively, and they were less frequently detected in the surface water samples of GTR. In the upstream rivers, ACE, CAF, DTZ, OTC, CTC, and OFL were detected in all surface water samples, while the detection frequency of the other target PPCPs was above $71 \%$, except for CBZ (42.9\%) and TYL (0\%). With the exception of CBZ and TYL, the other sixteen target PPCPs were frequently detected (70-100\%) in surface water because of their widespread use and high water solubility. CAF was the most abundant PPCP, with the highest mean concentration of $338 \mathrm{ng} \mathrm{\textrm {L } ^ { - 1 }}$, followed by ACE, with a mean concentration of $302 \mathrm{ng} \mathrm{L}^{-1}$ in the surface water of upstream rivers. The detection frequencies of CBZ and TYL were low, with a detection frequency of $42.9 \%$ and not detected, respectively. The detection frequencies of the other fourteen target PPCPs were $71.4-100 \%$, with mean concentrations between 2.23 and $32.1 \mathrm{ng} \mathrm{L}^{-1}$.

An assessment of the distribution of PPCPs in surface water showed that five non-antibiotic pharmaceuticals (N-APs [ACE, CAF, DTZ, CBZ, and FXT]) were the predominant PPCPs (74.2\%) in GTR and upstream rivers (79.4\%) in all samples (Fig. 2). In this area, the five N-APs were of particular concern due to their extensive therapeutic use in humans. They were the most frequently detected PPCPs in surface water in GTR and upstream rivers. They were the most frequently detected PPCPs in surface water because of their widespread use in the GTR basin. CAF and ACE were of particular concern. Of the five NAPs, CAF was detected with the highest mean concentration

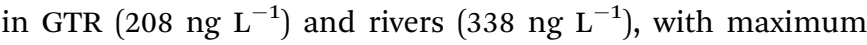
concentrations of 620 and $708 \mathrm{ng} \mathrm{L}^{-1}$, respectively, followed by ACE, which was also detected with a high mean concentration of $155 \mathrm{ng} \mathrm{L}^{-1}$ in GTR and $302 \mathrm{ng} \mathrm{L}^{-1}$ in rivers. CAF is present in a wide range of consumer products, such as coffee, tea, soft drinks, chocolate, and painkillers and has been reported in environmental samples worldwide, with a high occurrence, resulting in it being proposed as a biomarker for anthropogenic inputs into the aquatic environment. ${ }^{\mathbf{1 4 , 3 2 , 3 3}}$ The high occurrence

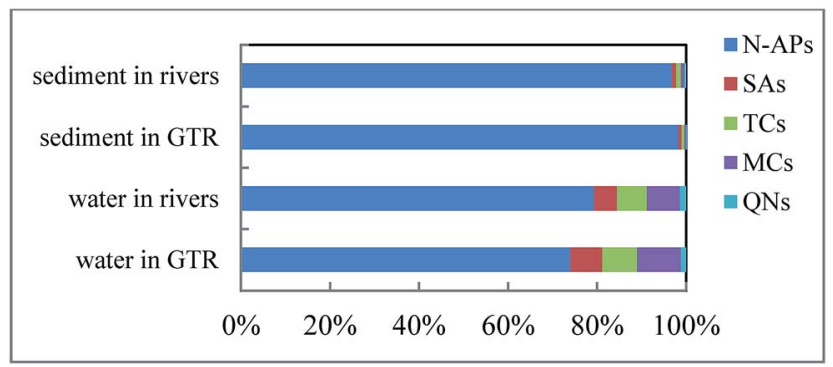

Fig. 2 Composition profiles of pharmaceutical and personal care products (PPCPs) in surface water and sediments (non-antibiotic pharmaceuticals [N-APs], sulfonamides [SAs], tetracyclines [TCs], macrolides [MCs], quinolones [QNs]). 
of CAF in GTR and its upstream rivers suggested that there were inputs from both wastewater treatment plants and untreated wastewaters, and indicated a high consumption of caffeinebearing products. These products are likely to be tea and soft drinks, which are the two most widely consumed beverages in China. ACE is an antipyretic and analgesic drug, which is heavily used and is used worldwide, mainly to treat influenza. ACE is ranked as one of the top three prescription drugs in England, ${ }^{34}$ and is also one of the top 200 prescription drugs in the United States. ${ }^{35}$ The global production output of ACE is 200000 tons per year. China is the second largest ACE manufacturing country, with many different cold medicines used in China containing ACE. ${ }^{36}$ It is reported that during the therapeutic use of ACE, about $58-68 \%$ of the dose is not absorbed by the human body. ${ }^{37}$ It is commonly directly released into the environment in its primary form or as a metabolite through urine or excrement.

SDZ, SMX, and TMP (TMP is sulfonamide synergistic agent, and usually used in combination with SMX. So we consider it as the SAs in this study) are the most widely used sulfonamide (SA) antibiotics for humans, while SMZ is the most widely used antibiotic for animals. In this study, the detection frequency of these four SAs (SDZ, SMX, SMZ, and TMP) at levels above their LOQs in surface water was greater than 69 and $71 \%$ in the 14 water samples from GTR and its upstream rivers, respectively. The highest detection frequency was $85.7 \%$ for SDZ, followed by TMP, SMX, and SMZ in GTR, while in the water samples from the upstream rivers the highest detection frequency was $85.7 \%$ for SMX and TMP, followed by SDZ and SMZ. Among these four compounds, the highest mean concentration was recorded for SMX at $15.0 \mathrm{ng} \mathrm{L}^{-1}$ in GTR and $17.2 \mathrm{ng} \mathrm{\textrm {L } ^ { - 1 }}$ in the rivers. Compared with previous studies, which found that SAs, and especially SMX, had a high rate of occurrence, the levels of SA pollution in the surface water of GTR and the upstream rivers was not very high. The concentrations of SA contaminants in this study were at an intermediate level compared with the levels reported in previous studies. In comparison, the SMX concentrations in the surface water from GTR and upstream rivers were much lower than the levels reported previously in the surface water of Huangpu River, in which the mean concentration was $260 \mathrm{ng} \mathrm{L^{-1 }}$ as it passed through Shanghai City in China, ${ }^{38}$ and in the surface water of Taihu Lake, in which

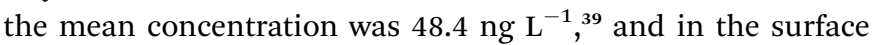
water of Seine River in France, in which the mean concentration was $40 \mathrm{ng} \mathrm{L}^{-1} .^{40}$ However, the mean concentration of SMX in the surface water of GTR and the upstream rivers was much higher than that reported in the Pearl River Estuary in south China, ${ }^{23}$ with a mean concentration of $4.65 \mathrm{ng} \mathrm{L}^{-1}$ in both the dry and wet seasons. The mean concentrations of SMX in the surface water of GTR and the upstream rivers were similar to those reported in the Pearl River Estuary in south China, with a mean concentration of $12.4 \mathrm{ng} \mathrm{L}{ }^{-1}$ in the wet season, ${ }^{23}$ and were also similar to levels reported in the surface water of Dongjiang River in south China, in which the mean concentration was $14.9 \mathrm{ng} \mathrm{L}{ }^{-1}$. $1^{1}$

Among the four tetracycline (TC) antibiotics investigated (OTC, TC, CTC, and DOX), all had a detection frequency greater than 50\%. For humans and animals, OTC, TC, and DOX are widely used TC antibiotics, while CTC is the most widely used antibiotic for humans. CTC had the highest detection frequency of $100 \%$, followed by OTC, TC, and DOC at 92.9, 71.4, and $57.1 \%$, respectively. The highest mean concentration was determined for OTC at $15.2 \mathrm{ng} \mathrm{L}^{-1}$, which also had the highest detection frequency of the four TCs. DOX and TC had the lowest mean concentrations of the four TCs in surface water from GTR at 5.19 and $6.39 \mathrm{ng} \mathrm{L}^{-1}$, respectively. Compared with the results of previous studies, in which TCs, and especially OTC and CTC, were reported to have a high rate of occurrence, the levels of TC pollution were not very high in GTR. In comparison, the concentrations of OTC in the surface water of GTR were much lower than in Huangpu River, Shanghai City in China ${ }^{38}$ and Taihu Lake, China, in which mean concentrations of 78.3 and $44.2 \mathrm{ng} \mathrm{L}{ }^{-1},{ }^{39}$ respectively, have been reported. However, the mean concentration of CTC was similar to the levels reported previously in Huangpu River, Shanghai City ${ }^{38}$ and the Pearl River Estuary in China, ${ }^{23}$ with mean concentrations of 4.20 and $7.37 \mathrm{ng} \mathrm{L^{-1 }}$, respectively.

AMZ and ERY are the most widely used macrolides (MC) antibiotics for humans, while TYL and LIN are mainly used to cure illness in animals. Among the four MCs investigated (AMZ, ERY, TYL, and LIN), three had a detection frequency greater than $85 \%$, while the detection frequency of TYL was lower at $14.3 \%$. LIN had the highest detection frequency of $92.9 \%$, followed by AMZ and ERY, which were both 85.7\%. The highest mean concentration was determined for LIN at $23.5 \mathrm{ng} \mathrm{L}^{-1}$, with a detection frequency of $92.9 \%$. TYL had the lowest mean concentration of the four MCs at $0.21 \mathrm{ng} \mathrm{L}^{-1}$, and also had the lowest detection rate of $14.3 \%$. In the upstream rivers, three of the four MCs had a detection frequency greater than $70 \%$, while TYL was not detected. ERY had the highest detection frequency of $92.9 \%$, followed by AMZ and LIN, which were 78.6 and $71.4 \%$. The highest mean concentration was determined for ERY at $32.1 \mathrm{ng} \mathrm{L}^{-1}$. TYL was not detected in 14 water samples from the rivers. In previous studies, MCs, especially ERY, were reported to have high detection frequencies, although concentrations in the surface water of GTR and upstream rivers were not very high. The concentrations of MC contaminants in this study were at an intermediate level compared with the levels reported in previous studies. In comparison, the ERY concentrations in the surface water of GTR and upstream rivers were much lower than those reported previously in the surface water of the central and lower reaches of the Yangtze River in China ${ }^{\mathbf{1 4}}$ and Taihu Lake, ${ }^{39}$ where reported concentrations were 296 and $109.1 \mathrm{ng} \mathrm{L}{ }^{-1}$. However, the mean concentration of ERY in the surface water of the upstream rivers was much higher than reported previously in the Taff River in the $\mathrm{UK}^{42}$ and Mekong River in Vietnam, ${ }^{43}$ where the concentrations were 4.0 and 9.0$12.0 \mathrm{ng} \mathrm{L}{ }^{-1}$, respectively. The mean concentrations of ERY were the same level in the surface water samples of GTR in Poyang Lake, and Dongting Lake, where the reported concentrations were 1.10 and $8.40 \mathrm{ng} \mathrm{L}^{-1}$, respectively. ${ }^{14}$ Also the mean concentration of ERY in the surface water of upstream rivers was similar to the levels reported previously in the Pearl River Estuary (wet season) in south China, ${ }^{23}$ Chao Lake, ${ }^{14}$ and 
Baiyangdian Lake, ${ }^{25}$ with mean concentrations of 29.9, 20.7, and $19.5 \mathrm{ng} \mathrm{L}^{-1}$, respectively.

Quinolones (QN) are some of the most widely used antibiotics for humans and animals. OFL was the only QN antibiotic detected in this study, with a high detection frequency of $100 \%$ and mean concentrations of 13.8 and $15.2 \mathrm{ng} \mathrm{L}^{-1}$ in surface water samples from GTR and upstream rivers, respectively. Compared with previous studies, in which a high rate of occurrence of OFL was reported, the levels of QN pollution in the surface water of GTR and upstream rivers were not very high. The concentrations were at an intermediate level compared with those reported in previous studies. In comparison, the concentration of OFL in the surface water of GTR and upstream rivers was much lower than the levels reported in the surface water of Qiantang River, in which the range was 60$85 \mathrm{ng} \mathrm{L}^{-1}$,4 $^{-1}$ Taihu Lake $\left(32.2 \mathrm{ng} \mathrm{L^{-1 }}\right),{ }^{39}$ the Seine River (30.0 $\mathrm{ng} \mathrm{L}^{-1}$ ) in France, ${ }^{40}$ and Duliujian River in Tianjin (49.2$\left.89.4 \mathrm{ng} \mathrm{L}^{-1}\right) \cdot{ }^{45}$ However, the concentrations of OFL were slightly higher than those reported in the surface water of the Pearl River Estuary in China, where concentrations of 7.10 and $6.16 \mathrm{ng} \mathrm{L}^{-1}$ were reported in the wet and dry seasons, respectively. ${ }^{23}$ This suggests that different antibiotics were used in the different geographic regions of China.

Among the 28 surface water samples of GTR and upstream rivers, the total PPCP concentrations from sites L10-L14 (843$1319 \mathrm{ng} \mathrm{L}^{-1}$ ), and R01-R06 and R11, R13 (626-1895 $\mathrm{ng} \mathrm{L}^{-1}$ ) were greater than those from sites L01-L09 (132-370 $\left.\mathrm{ng} \mathrm{L}^{-1}\right)$ in GTR, and R07-R12 and R14 (281-587 $\left.\mathrm{ng} \mathrm{L}^{-1}\right)$ in the upstream rivers (Fig. 3). The highest concentrations of the 18 PPCPs was at site L13 (1319 $\left.\mathrm{ng} \mathrm{L}^{-1}\right)$ from GTR and site R02 (1895 $\left.\mathrm{ng} \mathrm{L}^{-1}\right)$ from the upstream rivers. In GTR, the total concentrations of the 18 PPCPs showed that levels in the southwest of the reservoir were much higher than in the northeast. In the flow direction of upstream rivers, the total concentrations of the 18 PPCPs tended to increase in the rivers, which showed that PPCPs were input to rivers downstream of Zhangjiakou City. As the perennial inflowing river to GTR, Yongding River may make a significant contribution to the PPCP input to GTR. It has been reported that Yongding River receives a huge amount of domestic sewage and industrial wastewater from Zhangjiakou
City. Therefore, the sewage discharged from Zhangjiakou City, with over three million residents, was likely to be the main source of PPCPs in GTR. Human activities play a key role in the distribution of PPCPs in GTR. Low levels of total PPCPs in surface water samples were found in the northeast part of GTR, where there was little disturbance by human activities and little input from other rivers. These results indicate that GTR might be influenced to some extent by the continuous discharge of wastewater by the residents of local coastal areas.

\section{PPCPs in sediments}

In sediments, three of the 18 selected PPCPs had high detection rates, with a $100 \%$ detection frequency in GTR; five of the 18 selected PPCPs had high detection rates, with a $100 \%$ detection frequency in upstream rivers (Table 1). In GTR, the detection rates of ACE, CAF, and OFL were $100 \%$, while FXT and TMP were only 23.1 and $38.5 \%$, respectively, while the detection rates of other thirteen PPCPs were between 53.9 and 92.3\%. In upstream rivers, the detection frequency of ACE, CAF, CBZ, TC, and CTC were $100 \%$, while TYL was the least frequently detected PPCP, with a detection rate of $30 \%$. The detection rates of the other twelve PPCPs were between 50 and $90 \%$. ACE and CAF were the predominant pollutants, with high detection rates and high mean concentrations in GTR and upstream rivers. The mean concentrations of ACE and CAF were 529 and $1430 \mathrm{ng} \mathrm{g}^{-1}$ (dry weight, [dw]), respectively, in GTR and 202 and $1020 \mathrm{ng} \mathrm{g}^{-1}$, respectively, in upstream rivers.

All five N-APs were detected in the sediments from GTR and upstream rivers. In GTR, the detection frequencies of CAF and ACE were $100 \%$ among the 23 sediment samples in GTR and upstream rivers, while CBZ and DTZ had detection frequencies of 76.9 and $84.6 \%$, respectively. FXT was the least frequently detected N-AP, with a detection rate of $23.1 \%$. In upstream rivers, the detection frequencies of ACE, CAF, and CBZ were $100 \%$, followed by DTZ and FXT, with detection frequencies of 90 and $80 \%$, respectively. ACE and CAF had high mean concentrations of 529 and $1430 \mathrm{ng} \mathrm{g}^{-1}$, respectively, in GTR, 202 and $1020 \mathrm{ng} \mathrm{g}^{-1}$, respectively, in upstream rivers. The mean concentrations of the other three N-APs were below $10.0 \mathrm{ng} \mathrm{g}^{-1}$

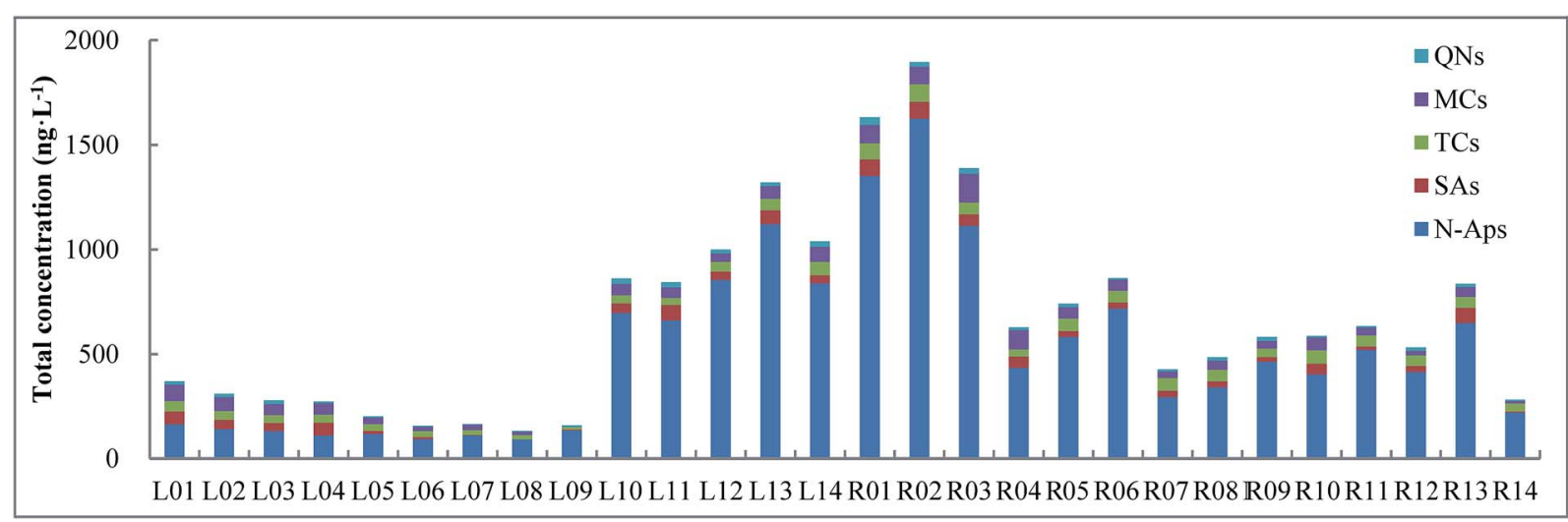

Fig. 3 Concentrations of pharmaceutical and personal care products (PPCPs) in surface water samples (ng L ${ }^{-1}$ ) (non-antibiotic pharmaceuticals [N-APs], sulfonamides [SAs], tetracyclines [TCs], macrolides [MCs], quinolones [QNs]). 
in GTR and upstream rivers. The mean concentration of CAF in GTR and upstream rivers were much higher than in previous studies, in which the maximum concentration was $29.7 \mathrm{ng} \mathrm{g}^{-1}$ in San Francisco Bay, USA ${ }^{46}$ and the mean concentration was $23.4 \mathrm{ng} \mathrm{g}^{-1}$ in Todos os Santos Bay and the north coast of Salvador, Bahia, Brazil. ${ }^{17}$ In comparison, the mean concentrations of ACE in the sediments of GTR were much higher than in previous studies, in which the maximum concentration was $222 \mathrm{ng} \mathrm{g}^{-1}$ at sites in the Ebro River Basin in Spain, ${ }^{47}$ while they were similar to the levels in upstream rivers in this study. The mean concentration of CBZ was 3.40 and $6.73 \mathrm{ng} \mathrm{g}^{-1}$ in GTR and the upstream rivers, respectively. The mean concentration of $\mathrm{CBZ}$ was similar to that reported in marine sediments in Todos os Santos Bay and the north coast of Salvador, Bahia, Brazil, with a mean concentration of $4.81 \mathrm{ng} \mathrm{g}^{-1} \cdot{ }^{17}$

The detection frequency of the four SAs at levels above their LOQs in sediments was above $50 \%$ in the 23 sediment samples in GTR and upstream rivers, except TMP in GTR. The highest mean concentration was determined for SMX at $9.93 \mathrm{ng} \mathrm{g}^{-1}$ in GTR, while the mean concentrations of the other three SAs in GTR and upstream rivers were below $3.50 \mathrm{ng}^{-1}{ }^{-1}$. Compared with previously reported concentrations, SMX in sediments from GTR was present at intermediate concentrations. The concentration of SMX was higher than reported in the Huangpu River, with a mean concentration of $0.2 \mathrm{ng} \mathrm{g}^{-1},{ }^{38}$ and lower than reported in Taihu Lake ${ }^{39}$ and the Pearl River, ${ }^{23}$ with mean concentrations of 16.1 and $12.4 \mathrm{ng} \mathrm{g}^{-1}$, respectively.

The detection frequency of the four TCs at levels above their LOQs in sediments was above $60 \%$ in the 23 sediment samples from GTR and the upstream rivers. The mean concentrations of TCs were similar among the different sampling sites, with a range from 1.67 to $5.06 \mathrm{ng} \mathrm{g}^{-1}$. Compared to the mean concentrations of OTC, TC, and CTC in Taihu Lake, China, at $52.8,47.9$, and $19.0 \mathrm{ng} \mathrm{g}^{-1}$, respectively, ${ }^{39}$ the concentrations of SAs in the sediments of GTR and upstream rivers were lower, while the mean concentration of TCs was similar to that reported in sediment samples in Huangpu River, with a concentration range of $2.40-7.00 \mathrm{ng} \mathrm{g}^{-1} .^{38}$

Among the 23 sediment samples in GTR and the upstream rivers, the detection frequency of the four MCs at levels above their LOQs in sediments was above 50\%, except TYL (30\%) in upstream rivers. The mean concentrations ranged from 0.64 to $4.44 \mathrm{ng} \mathrm{g}^{-1}$. The mean concentrations of ERY in GTR and upstream rivers were lower than the level reported $\left(10.2 \mathrm{ng}^{-1}\right)$ in the Pearl River in southern China. ${ }^{23}$ The mean concentration of ERY was similar to that reported in sediment samples in Baiyangdian Lake, with a mean concentration of $0.59 \mathrm{ng} \mathrm{g}^{-1} \cdot{ }^{25}$

OFL was the only QN antibiotic investigated in this study, and had a high detection frequency of 100 and $70 \%$ in GTR and upstream rivers, with mean concentrations of 3.47 and $4.27 \mathrm{ng} \mathrm{g}^{-1}$, respectively. The mean concentration was similar to that reported in Huangpu River, ${ }^{38}$ Pearl River, ${ }^{23}$ Yellow River, Haihe River, and Liaohe River, ${ }^{22}$ with mean concentrations of $6.50,3.50,3.07,10.3$, and $3.56 \mathrm{ng} \mathrm{g}^{-1}$, respectively. However, it was lower than the concentration of $16.5 \mathrm{ng} \mathrm{g}^{-1}$ reported in Taihu Lake. ${ }^{39}$

\section{Relationship between PPCPs and water quality parameters}

There are various sources of DOC, TN, TP, and $\mathrm{NH}_{3}-\mathrm{N}$, such as industrial wastewater, municipal wastewater, agricultural surface runoff, and aquaculture. Details of these water quality parameters in GTR and the upstream rivers are provided in Table S4 in the ESI. $\dagger$ As with PPCPs, once in the aquatic environment, they are subject to sorption, dilution, and degradation processes. PPCPs are mainly man-made chemicals, and their presence can be linked to specific human or veterinary use. The Pearson correlation coefficients between PPCP concentrations and water quality parameters were calculated and are presented in Table 2. A positive correlation was observed for FXT, TMP, and TC with TN. FXT and TMP are pharmaceuticals for human use, while TCs are man-made chemicals used in pharmaceuticals for human use and veterinary medicine. For FXT, TMP, and TC, the positive correlation with TN suggests that both municipal wastewater and animal waste is their primary source, and that their environmental fate (degradation and transformation) in water was similar to that of TN. A positive correlation was observed between TP and both FXT and CBZ, with CBZ used in both human and veterinary medicine. However, TP can be derived from surface runoff from fertilized soil, animal waste, or domestic wastewater. The positive correlation between TP and FXT and CBZ suggests that domestic wastewater, animal waste, and surface runoff from fertilized soil were their most important sources, and that their environmental fate was similar to that of TP in water.

Yang et al. (2013) reported positive correlations between ACE, CAF, SMX, and ciprofloxacin and $\mathrm{TN}$ and $\mathrm{NH}_{3}-\mathrm{N}$ in urban river water samples from the Pearl River Delta. ${ }^{48}$ In their study, significant correlations were observed between the PPCPs and $\mathrm{TN}$ and $\mathrm{NH}_{3}-\mathrm{N}$, which were attributed to inputs of municipal wastewater to the Guangzhou section of the Pearl River. The regions studied were well developed and densely populated,

Table 2 Pearson correlation coefficients $(r)$ between PPCPs concentrations and water quality parameters

\begin{tabular}{lrrrr}
\hline Analytes & \multicolumn{1}{c}{ DOC } & \multicolumn{1}{l}{ TN } & \multicolumn{1}{l}{ TP } & $\mathrm{NH}_{3}-\mathrm{N}$ \\
\hline ACE & -0.165 & 0.393 & 0.061 & -0.044 \\
CAF & -0.200 & 0.193 & -0.016 & -0.015 \\
DTZ & -0.071 & -0.303 & -0.190 & -0.036 \\
CBZ & 0.345 & 0.486 & $0.549^{a}$ & -0.145 \\
FXT & 0.160 & $0.548^{a}$ & $0.530^{a}$ & 0.123 \\
SDZ & -0.025 & -0.034 & -0.174 & -0.016 \\
SMX & 0.052 & 0.008 & 0.073 & -0.051 \\
SMZ & 0.096 & 0.122 & -0.063 & -0.100 \\
TMP & 0.085 & $0.531^{a}$ & 0.412 & -0.037 \\
OTC & -0.301 & 0.418 & 0.085 & -0.280 \\
TC & 0.149 & $0.530^{a}$ & 0.314 & -0.046 \\
CTC & -0.002 & 0.192 & 0.227 & -0.304 \\
DOX & -0.413 & 0.219 & -0.180 & 0.260 \\
AZM & 0.155 & 0.467 & 0.176 & 0.199 \\
ERY & -0.012 & -0.184 & -0.093 & -0.059 \\
TYL & -0.006 & 0.004 & 0.048 & 0.106 \\
LIN & 0.088 & -0.448 & -0.292 & -0.227 \\
OFL & -0.129 & 0.255 & 0.127 & -0.303 \\
${ }^{a}$ Significant correlation $(P<0.05)$. & &
\end{tabular}


with little agricultural activity. Wu et al. reported positive and negative correlations of ERY and CAF with $\mathrm{NH}_{3}-\mathrm{N}$ in the lower Yangtze River. ${ }^{14}$ In the study, only ERY and CAF were significantly correlated with $\mathrm{NH}_{3}-\mathrm{N}$. The study areas were so large that the water bodies were under the influence of multiple sources, and the measured water quality parameters may not have reflected the contamination status with respect to PPCPs. In the current study, samples were collected from GTR and its upstream rivers. There is a population of at least three million around the GTR basin. Most of their domestic wastewater, animal waste, and aquaculture waste water is discharged into the rivers and ultimately enters the GTR.

\section{Environmental risk assessment}

Using the maximum MEC, a worst-case scenario environmental risk assessment was conducted for the selected PPCPs. The RQ values of the eighteen PPCPs measured in GTR and the upstream rivers are listed in Table S5 in the ESI. $\dagger$ In this study, most RQ values were below 0.01 in GTR and the upstream rivers, which indicates that the risk from PPCPs was relatively low. However, the RQ values of CAF in upstream rivers, and TMP and OTC in GTR and upstream rivers were higher than 0.01, indicating a relatively low risk. The RQ value of ERY in GTR was 0.689 , which indicated a medium risk. There was a high risk value for ERY in upstream rivers, with an RQ value of 1.592 . High RQ values for ERY were reported previously in the Yangtze River, with the highest RQ value of $20.20,{ }^{14}$ which was more than 10 times higher than in any of the water samples studied here. The high risks associated with ERY could be attributed to their relatively high concentrations and the low PNEC value.

The concentrations of PPCPs in the water body can be influenced by the time of sampling, with the resulting seasonal variation therefore affecting the result of any risk assessment. Many previous studies have shown that PPCP concentrations tend to be higher during dry seasons as a result of dilution in the wet season. ${ }^{49}$ In the current study, the water and sediment samples were collected in summer, corresponding to the wet season in the GTR basin, and therefore should reflect the low environmental risk limit.

\section{Conclusion}

Eighteen selected PPCPs were detected in surface water and sediments from GTR and its upstream rivers. Most of these compounds had a high detection frequency. The total concentrations of five N-APs, especially ACE and CAF, in surface water were more than 5-10 times higher than the corresponding concentrations of SAs, TCs, MCs, and QNs, while were more than 45-100 times higher than the corresponding concentrations of SAs, TCs, MCs, and QNs in sediment samples. Compared with the major rivers and lakes in China and those worldwide, the concentrations of the 18 selected PPCPs were considered to be at an intermediate level, except for ACE and CAF. The total concentrations of PPCPs in the surface water of upstream rivers were higher than in GTR, while the total concentrations of PPCPs in the sediments of GTR were higher than in upstream rivers. The worst-case scenario from an environmental risk assessment indicated potential risks from ERY toward sensitive species in GTR and its upstream rivers. Further information regarding the relationship between the concentrations of PPCPs and water quality parameters need to be obtained in future studies.

\section{Conflicts of interest}

There are no conflicts to declare.

\section{Acknowledgements}

This work was supported by the Major Science and Technology Program for Water Pollution Control and Treatment (2018ZX07111-002) and the Beijing Municipal Science and Technology Plan Project (Z171100000717010) and (Z171100004417025).

\section{References}

1 H. P. H. Arp, Environ. Sci. Technol., 2012, 4259-4260.

2 J. Fawell and C. N. Ong, Int. J. Water Resour. Dev., 2012, 28, 247-263.

3 A. B. A. Boxall, M. A. Rudd and B. W. Brooks, Environ. Health Perspect., 2012, 120, 1221-1229.

4 Q. W. Bu, B. Wang, J. Huang, S. B. Deng and G. Yu, J. Hazard. Mater., 2013, 262, 189-211.

5 R. Hirsch, T. Ternes, K. Haberer and K. L. Kratz, Sci. Total Environ., 1999, 225, 109-118.

6 C. I. Kosma, D. A. Lambropoulou and T. A. Albanis, Sci. Total Environ., 2014, 466-467, 421-438.

7 N. Gottschall, E. Topp, C. Metcalfe, M. Edwards, M. Payne, S. Kleywegt, P. Russell and D. R. Lapen, Chemosphere, 2012, 87, 194-203.

8 K. Kümmerer, Chemosphere, 2009, 75, 417-434.

9 S. C. Kim and K. Carlson, Water Res., 2006, 40, 2549-2560.

10 H. M. Zhang, P. X. Liu, Y. J. Feng and F. L. Yang, Mar. Pollut. Bull., 2013, 73, 282-290.

11 A. M. Ali, H. T. Rønning, W. M. Arif, P. Kallenborn and S. S. Al-lihaibi, Chemosphere, 2017, 175, 505-513.

12 E. Carmona, V. Andreu and Y. Picó, Sci. Total Environ., 2014, 484, 53-63.

13 E. Carmona, V. Andreu and Y. Picó, J. Pharm. Biomed. Anal., 2017, 146, 117-125.

14 C. X. Wu, X. L. Huang, J. D. Witter and A. L. Spongberg, Ecotoxicol. Environ. Saf., 2014, 106, 19-26.

15 Y. Y. Yang, X. H. Cao, M. M. Zhang and J. Wang, Environ. Sci. Pollut. Res., 2015, 22, 17644-17652.

16 C. X. Yan, Y. Yang, J. L. Zhou, M. Liu, M. H. Nie and H. Shi, Environ. Pollut., 2013, 175, 22-29.

17 M. Beretta, V. Britto, T. M. Tavares, S. M. T. D. Silva and A. L. Pletsch, J. Soils Sediments, 2014, 14, 1278-1286.

18 E. Vulliet, C. Cren-Olivé and M. F. Grenier-Loustalot, Environ. Chem. Lett., 2011, 9, 103-114.

19 L. Fent, A. A. Weston and D. Caminada, Aquat. Toxicol., 2006, 76, 122-159. 
20 D. Mackay and L. Barnthouse, Integr. Environ. Assess. Manage., 2010, 6, 390-392.

21 J. L. Liu and M. H. Wong, Environ. Int., 2013, 59, 208-224.

22 L. J. Zhou, G. G. Ying, J. L. Zhao, J. F. Yang, L. Wang, B. Yang and S. Liu, Environ. Pollut., 2011, 159, 1877-1885.

23 X. M. Liang, B. W. Chen, X. P. Nie, Z. Shi, X. P. Huang and X. D. Li, Chemosphere, 2013, 92, 1410-1416.

24 T. Lin, S. Yu and W. Chen, Chemosphere, 2016, 152, 1-9.

25 W. H. Li, Y. L. Shi, L. H. Gao, J. M. Liu and Y. Q. Cai, Chemosphere, 2012, 89, 1307-1315.

26 R. Z. Liu, J. Liu, Z. J. Zhang, A. Borthwick and K. Zhang, Int. J. Environ. Res. Public Health, 2015, 12(12), 15269-15284.

27 T. Y. Wang, C. L. Chen, J. E. Naile, J. S. Khim, J. P. Giesy and Y. L. Lu, Bull. Environ. Contam. Toxicol., 2011, 87, 74-79.

28 EPA, 2007, http://www.caslab.com/EPAMethods/PDF/ 1694.pdf.

29 A. M. Jacobsen, B. Halling-sørensen and S. H. Hansen, J. Chromatogr. A, 2004, 1038, 157-170.

30 European Commission, Technical Guidance Document on Risk Assessment. Part II, European Commission Joint Research Centre, (EUR20418 EN/2), 2003.

31 M. D. Hernando, M. Mezcua, A. R. Fernándezalba and D. Barceló, Talanta, 2006, 69, 334-342.

32 R. Loos, B. M. Gawlik, G. Locoro, E. Rimaviciute, S. Contini and G. Bidoglio, Environ. Pollut., 2009, 157, 561-568.

33 C. X. Wu, J. D. Witter, A. L. Spongberg and K. P. Czajkowski, Water Res., 2009, 43, 3407-3416.

34 I. M. Sebastine and R. J. Wakeman, Process Saf. Environ. Prot., 2003, 81, 229-235.

35 X. Zhang, F. Wu, X. W. Wu and N. S. Deng, J. Hazard. Mater., 2008, 157, 300-307.
36 L. Zhang, China Pharm., 2002, 13, 11.

37 N. Muir, J. D. Nichols, M. R. Stillings and J. Sykes, Curr. Med. Res. Opin., 1997, 13, 491-500.

38 K. Chen and J. L. Zhou, Chemosphere, 2014, 95, 604-612.

39 J. Xu, Y. Zhang, C. B. Zhou, C. S. Guo, D. M. Wang, P. Du, Y. Luo, J. Wan and W. Meng, Sci. Total Environ., 2014, 497498, 267-273.

40 F. Tamtam, F. Mercier, B. L. Bot, J. Eurin, Q. T. Dinh, M. Clément and M. Chevreuil, Sci. Total Environ., 2008, 393, 84-95.

41 R. J. Zhang, G. Zhang, J. H. Tang, W. H. Xu, J. Li, X. Liu, Y. D. Zou, X. X. Chen and X. D. Li, Aquat. Ecosyst. Health Manage., 2012, 15, 201-218.

42 B. Kasprzyk-Horden, R. M. Dinsdale and A. J. Guwy, Water Res., 2009, 43, 363-380.

43 T. Kobayashi, F. Suehiro and B. S. Tuyen, FEMS Microbiol. Ecol., 2007, 59, 729-737.

44 H. Chen, X. Li and S. Zhu, Environ. Sci. Pollut. Res., 2012, 19, 2381-2389.

45 L. H. Gao, Y. L. Shi, W. H. Li, J. M. Liu and Y. Q. Cai, J. Environ. Monit., 2012, 14, 1248-1255.

46 S. L. Klosterhaus, R. Grace, M. C. Hamilton and D. Yee, Environ. Int., 2013, 54, 92-99.

47 B. F. Silva, A. Jelic, R. López-Serna, A. A. Mozeto, M. Petrovic and D. Barceló, Chemosphere, 2011, 85, 1331-1339.

48 X. Yang, F. Chen, F. G. Meng, Y. Y. Xie, H. Chen and K. Young, Environ. Sci. Pollut. Res., 2013, 20, 5864-5875.

49 W. H. Xu, G. Zhang, S. C. Zou, X. D. Li and Y. C. Liu, Environ. Pollut., 2007, 145, 672-679. 